\title{
CORRECTION
}

W) Check for updates

Cite this: J. Mater. Chem. A, 2020, 8 , 20191

DOI: $10.1039 / \mathrm{d} 0 \operatorname{ta} 90221 \mathrm{~g}$

rsc.li/materials-a

\section{Correction: Lithiation of $\mathrm{V}_{2} \mathrm{O}_{3}\left(\mathrm{SO}_{4}\right)_{2}-\mathrm{a}$ flexible insertion host}

Stephanie F. Linnell, ${ }^{a}$ Julia L. Payne, ${ }^{a}$ David M. Pickup, ${ }^{\text {b }}$ Alan V. Chadwick, ${ }^{\text {b }}$ A. Robert Armstrong ${ }^{a}$ and John T. S. Irvine ${ }^{\star a}$

Correction for 'Lithiation of $\mathrm{V}_{2} \mathrm{O}_{3}\left(\mathrm{SO}_{4}\right)_{2}$ - a flexible insertion host' by Stephanie F. Linnell et al., J. Mater. Chem. A, 2020, DOI: 10.1039/d0ta06608g.

The authors regret an error in the published article in which the name A. Robert Armstrong was given incorrectly as A. Robert Armstong. The corrected spellings of all author names are shown here.

The Royal Society of Chemistry apologises for these errors and any consequent inconvenience to authors and readers. 